tion-list always contains a number of inmates whose friends apply for their lection for an additional term of five years, so that the cases in the asylum not increased in the same ratio as the number of successful candidates. niesion by election into this asylum is now rendered easy of accomplishment.

)R. IRrLaND's BOOK, "The Blot upon the Brain," is to be translated into man. The French translation of this work, which is being prepared by Dr. gar Borillon, of Paris, is nearly finished, and will be published in November. "Blot" has been prohibited by the ever-vigilant Russian censorship. This o doubt owing to the chapter on the hereditary insanity of the Romanoffs, I the historical illustrations about the miseries which insane monarchs have ised to their subjects. We hope Dr. Ireland's article in the present Number the late King of Bavaria will not share a like fate in that country.

\title{
Obituary.
}

\section{JAMES ALEXANDER EAMES, M.D.}

We believe that the decease of Dr. Eames, at the age of 53, is the first instance a President of the Medico-Psychological Association dying during his term of ice. Those who attended the forty-fourth annual meeting held at Cork last ar under his presidency had no reason to foresee that at the next anniversary i seat wonld be empty. Last autumn he visited Belgium, and was present at - Antwerp Congress of Mental Medicine; he joined the excursion to Gheel, in lioh he took a lively interest, and returned home in usual health and full of irits. Nothing, so far as we are aware, occurred to injure his health until ne last, when he was attacked with a carbuncle on the neck, which did not i some time excite alarm, but was followed in the course of a few weeks by eat prostration, and finally by death on Saturday, the 17th of July. His sdical attendants, Drs. Hobart, Townsend, and Deputy-Inspector-Steneral tmes, appear to have taken an encouraging view of the case till nearly the 3t. In his death a genial warm-hearted physician and a sincere friend paseed 1ay. His bonhomie and ready speech, his laugh and good-natured expresin, will be sorely missed in the family circle and the institution over which he led, loved by his colleagues and trusted by his committee. It was after Ilding the post of assistant-surgeon in the Crimean War, in which position he itained sereral marks of distinction, that he studied mental disorders, and was pointed Medical Superintendent of the Lettarkenuy Lunatic Asylum. Thirteen ars ago the then superintendent of the Cork Asylum (Dr. Power) died, and r. Fames, after having been eight years at the above-mentioned institution, as appointed his successor. It is said that this appointment was due in good easure to the influence of the Duke of Cambridge, who, when wounded in the rimea, received surgical attention from Dr. Eames. That his management of 10 Cork Asylum was successful, and indicated the fertile resources of the iperintendent, will be allowed by those members of our Association who were esent at the meeting and had an opportunity of going over the institution.

Dr. Eames contributed several papers to the medical journals of general iterest. He was always ready to introduce new remedies and appliances into te asylum, and never despised them, however homely and simple they might be.

We regret to find that Dr. Eames has not accumulated wealth, and that his ifo and family aro left unprovided for. Onder these circumstances an 
" Eames Fund" has been started, and we would enlist the sympathies of our readers on behalf of the subjoined appeal :-

\section{The LATE DR. EAMms.}

SIR,- It having come to the knowledge of some of the friends of the late $\mathrm{Dr}$. Eames, Resident Medical Superintendent of the Cork District Lunatio Asylum, that his family, owing to his premature and unexpectel death, is left in a very unprovided-for position, it was resolved, at a meeting held at the Mayor's Office, Cork, on the 22nd inst., the Mayor in the chair -

"That thle fact should be brought under the notice of Dr. Eames' many friends in Cork and eleewhere, in the hope that a testimon ial of a substantial character may be eubof the founger members

To carry out this laudable object, a committee was appointed, to whom subscriptions may be sent, as also to the different Banks in Cork.

Earnestly soliciting your co-operation, Signed on behalf of the Committee,

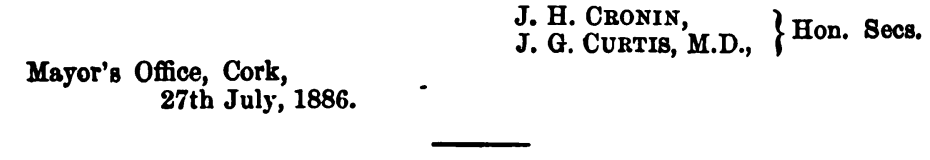

JOSEPH LALOR, M.D.

It is our painful task to record in our obituary the death of another Irish member of our Association, the late Medical Superintendent of the Richmond Asylum, Dublin, the excellent and kind-hearted Dr. Joseph Lalor. He may be said to have died in harness, having been engaged till within a few weeks of his death in the duties which occupied his time and thought for so many years. Formerly Resident Physician at the Kilkenny Asylum, he was appointed in 1857 to the Dublin Asylum, which is the public institution for poor lanatics in the counties of Dublin, Wicklow, and Louth, the town of Drogheda as well as the city of Dublin.

It is stated on good authority * that at that period, refractory patients were confined in cells for most of the day as well as the night, receiving their food in such a way as best suited the convenience of the attendants. Open-air exercise was rarely permitted, and then only in the dark confined yards or sheds surrounded by stone walls. All this was changed by Dr. Lalor; better grounds were prepared, games were introduced, and the general comfort of the patients was attended to. Dr. Lalor, as is well known, enthusiastically carried out the school system at the Richmond Asylum, and it was an unceasing source of regret to him that so few superintendents would take the necessary trouble to secure its success.

It should be stated that for two years before he became Superintendent a school had been in operation on the female side under an excellent schoolmistress. It was Dr. Lalor who introduced the same system for the male patients, and he obtained additional teachers, trained under the National Board, for the female school. Singing and music were much cultivated, while object and picture lessons were given, as well as others in natural history and geography. At the Exhibition held some years ago in Dublin, drawings, paint. ings, and industrial work, all executed by the patients, attracted considerable attention. Along with the schools, concerts were given every fortnight, or even weekly, which, common as they now are, were rare when Dr. Lalor organized

"Bee the "Irish Mimes," August 5, 1886, to which we are indebted for some of the particulares whiah follow. 